\title{
FETAL DUCTUS VENOSUS FLOW VELOCITY WAVEFORMS AND MATERNAL SERUM AFP BEFORE AND AFTER FIRST-TRIMESTER TRANSABDOMINAL CHORIONIC VILLUS SAMPLING
}

\author{
CHRISTOPH BREZINKA*, ADRIANA M. HAGENAARS $\dagger$, JURIY W. WLADIMIROFF* AND FRANS J. LOS $\ddagger$ \\ *Department of Obstetrics and Gynaecology, Academic Hospital Rotterdam-Dijkzigt, Rotterdam, The Netherlands; \\ $\dagger$ Department of Teratology, Endocrinology and Perinatal Screening, National Institute of Public Health and \\ Environmental Protection (RIVM), Bilthoven, The Netherlands; $\ddagger$ Department of Clinical Genetics, Academic \\ Hospital Rotterdam-Dijkzigt, Rotterdam, The Netherlands
}

Received 19 September 1994

Revised 6 March 1995

Accepted 18 March 1995

\begin{abstract}
SUMMARY
Doppler flow velocity waveform recording in the fetal ductus venosus and umbilical artery as well as maternal blood sampling for serum alpha-fetoprotein (MSAFP) was performed before and after transabdominal chorion villus sampling (TACVS) in 36 women of advanced maternal age ( $\geqslant 36$ years). Gestational age ranged between 11 and 13 weeks. No chromosomal anomaly was detected. No statistically significant difference was observed in ductus venosus velocity parameters or in the umbilical artery pulsatility index (PI) before and after CVS in 35 women with a normal pregnancy outcome. One case resulted in fetal loss. Post-CVS median MSAFP levels at 12 weeks ( 25 kIU/l) and 13 weeks $(35 \mathrm{kIU} / \mathrm{l})$ were significantly higher than pre-CVS levels. In three cases, post-CVS MSAFP levels were higher than $600 \mathrm{kIU} /$, correlating with feto-maternal transfusions of approximately $1.0-1.4 \mathrm{ml}$, i.e., of around 40 per cent of feto-placental blood volume. One of these cases displayed absence of fetal peripheral blood flow velocities and fetal bradycardia following TACVS, resulting in fetal loss 1 week later. The remaining two cases had a normal pregnancy outcome, but showed a more than 50 per cent reduction in ductus venosus velocity after TACVS, whereas umbilical artery PI remained unchanged. However, similar velocity changes were associated with only small feto-maternal transfusions. Umbilical artery PI values remained unchanged.
\end{abstract}

KEY wORDS: Doppler flow velocities; ductus venosus; chorion villus sampling

\section{INTRODUCTION}

Chorionic villus sampling (CVS) is associated with increased fetal loss, feto-maternal transfusion, and, as was demonstrated recently, terminal transverse limb defects (TTLDs) and other vascular disruptive disorders (Firth et al., 1991, 1994; Jahoda et al., 1993). A vascular aetiology of

Addressee for correspondence: Professor J. W. Wladimiroff, MD, PhD, Department of Obstetrics and Gynaecology, Academic Hospital Rotterdam-Dijkzigt, Dr Molewaterplein 40, 3015 GD Rotterdam, The Netherlands.
TTLDs related to either reduced fetal perfusion or thrombosis of the sampling site with subsequent embolization has been suggested (Burton et al., 1992; Brent, 1993).

Several studies have reported feto-maternal transfusion (FMT) as a result of the CVS procedure, with maternal serum alpha-fetoprotein (MSAFP) levels being a reliable parameter for the amount of fetal blood loss (Stabile et al., 1988; Los et al., 1989; Schmidt-Jensen et al., 1993). The median rise in MSAFP was significantly higher following transabdominal CVS compared with transcervical CVS, suggesting more extensive 
procedure-related placental damage with the transabdominal approach (Rodeck $e$ t al., 1993).

The question arises as to whether FMT would lead to changes in maternal uterine and fetal Doppler flow velocity waveforms. Doppler ultrasound has been applied in several studies to compare fetal and maternal blood flow before and after CVS procedures. No difference was found in the uterine arteries (Cohen-Overbeek et al., 1990) or fetal umbilical artery (Firth et al., 1991; Kofinas et al., 1992), suggesting that if changes in utero-placental perfusion occur as a result of TACVS, they are too small to affect flow velocity waveforms in these vessels.

Recently, a technique for recording flow velocities in the ductus venosus was described (Kiserud et al., 1991; Huisman et al., 1992). Oxygen-rich blood is shunted from the umbilical vein via the ductus venosus to the left atrium, ensuring optimal oxygen supply to the brain of the developing fetus. It has been demonstrated in the growth-retarded fetus that impaired utero-placental perfusion may be associated with marked changes in venous flow velocities including the ductus venosus (Kiserud $e t$ al., 1994).

The aim of the present study was to establish whether TACVS affects ductus venosus flow velocities and, if so, whether this is related to FMT as expressed by raised MSAFP levels.

\section{PATIENTS AND METHODS}

The study was approved by the Hospital Medical Ethics Committee. A total of 62 women who opted for transabdominal CVS (TACVS) because of advanced maternal age ( $\geqslant 36$ years) agreed to participate in the study. Gestational age ranged between 11 and 13 weeks (median 12 weeks). TACVS was carried out without local anaesthesia under continuous ultrasound monitoring (HitachiEUB 340, curved-linear array transducer with a carrier frequency of $3.5 \mathrm{MHz}$ ) using a $12 \mathrm{~cm}$ long 20-gauge needle without a stylet (TSK Supra, biopsy cut) as reported by Pijpers et al. (1988).

Maternal blood sampling was carried out from the cubital vein for MSAFP determination and Doppler flow velocity waveform recordings were obtained from the ductus venosus $20-30 \mathrm{~min}$ before and after the TACVS procedure, using a combined transabdominal real-time and pulsed Doppler system with a carrier frequency of 3.5 MHz for both real-time and Doppler (Hitachi
EUB 450, Japan). The system operates at power outputs of less than $100 \mathrm{MW} / \mathrm{cm}^{2}$ spatial peaktemporal average in both imaging and Doppler modes according to the manufacturer's specifications. The high pass filter was set at $100 \mathrm{~Hz}$. For visualization of the ductus venosus, the sample volume was placed immediately above the umbilical sinus in a cross-sectional view according to the method described by Huisman et al. (1993). Umbilical artery flow velocity waveforms were obtained from a free-floating loop of the umbilical cord.

All Doppler flow velocity waveforms were stored on hard copies and printed on a SONY-A4 printing device. A microcomputer linked to a graphics table was used for analysis of the Doppler recordings. An average of three consecutive waveforms with the highest velocities and with similar appearance was used to establish each value. Waveform analysis of the ductus venosus consisted of time-averaged velocity (TAV, $\mathrm{cm} / \mathrm{s}$ ), peak systolic velocity (PSV, $\mathrm{cm} / \mathrm{s}$ ), and peak diastolic velocity $(\mathrm{PDV}, \mathrm{cm} / \mathrm{s})$, and the ratio between these peak velocities. The pulsatility index (PI) in the umbilical artery was calculated according to Gosling and King (1975).

Maternal AFP levels were measured with AMERLEX $M$ second-trimester radio immunoassay kits for AFP (Kodak) and were expressed in absolute levels (kIU/h), since no reference values in the first trimester of pregnancy were available to allow the use of multiples of median values.

Pre- and post-CVS Doppler ultrasound data as well as maternal serum AFP levels were analysed by the Wilcoxon signed rank test. Pregnancy outcome was ascertained in all pregnancies investigated.

\section{RESULTS}

Of the total of 62 women who consented to the study, 26 dropped out for the following reasons: two miscarried prior to the CVS procedure; four subsequently declined the procedure; six withdrew their consent to participate in the study; and in six women CVS was not performed because of the presence of a retro-placental haematoma or because intestinal loops were situated in front of the uterus. In eight women, no technically acceptable Doppler signals could be obtained from the fetal ductus venosus within the allotted time of $10 \mathrm{~min}$ because of excessive fetal mobility or 


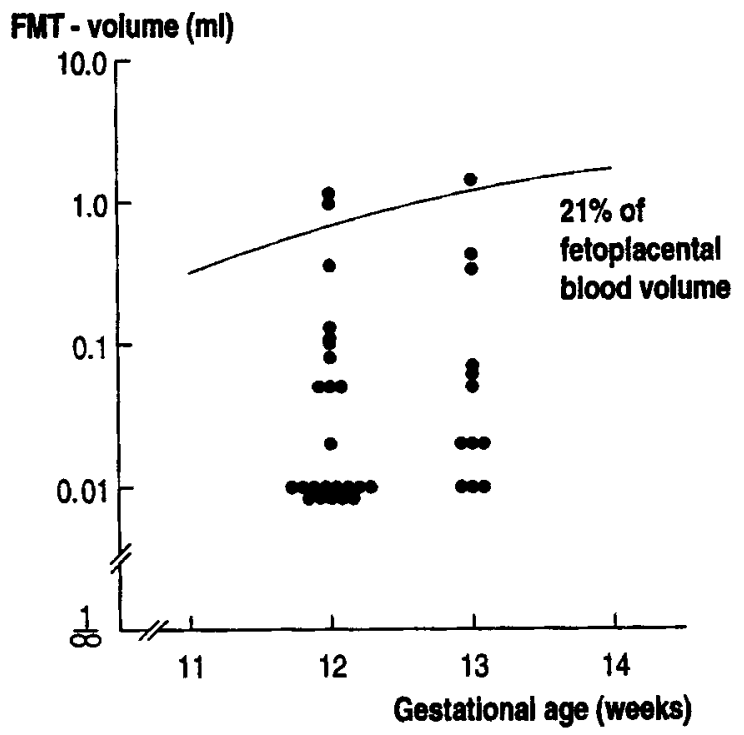

Fig. 1-Volumes of TACVS-induced feto-maternal transfusions in 36 women. The drawn link represents the critical border of 21 per cent of feto-placental blood volume

maternal obesity. A total of 36 women remained for further analysis.

There were 19 male and 17 female fetuses, and all were chromosomally normal. Thirty-five pregnancies were uneventful. In these pregnancies, birth weight was above the tenth centile for gestation (Kloosterman, 1970) in 33 cases and below the tenth centile in two cases. One pregnancy ended in fetal loss 1 week following the CVS procedure.

Post-CVS median MSAFP levels at 12 weeks (25, range $6-678 \mathrm{kIU} / \mathrm{l})$ and at 13 weeks $(35$, range 6-946 kIU/l) were significantly higher $(P<0.001)$ than pre-CVS median MSAFP levels (9, range 5-30 kIU/h and 11, range 6-23 kIU/l, respectively). The estimated volumes of feto-maternal transfusions are presented in Fig. 1.

Individual data from 35 women for the ductus venosus peak systolic velocity and time-averaged velocity before and after the CVS procedure are presented in Table I. There was no statistically significant difference. Pre-CVS and post-CVS data (mean $\pm \mathrm{SD}$ ) were $25 \cdot 1 \pm 12.6 \mathrm{~cm} / \mathrm{s}$ and $26.2 \pm 6.7 \mathrm{~cm} / \mathrm{s}$ for the peak diastolic velocity; $1.2 \pm 0.1$ and $1.2 \pm 0.1$ for the systolic/diastolic ratio; $2.5 \pm 0.2$ and $2.5 \pm 0.2$ for the umbilical artery PI; and $367.6 \pm 16.7 \mathrm{~ms}$ and $367.4 \pm 14.0 \mathrm{~ms}$ for the period time. Also for these data, there was no statistically significant difference.

In three cases, post-CVS MSAFP levels were higher than $600 \mathrm{kIU} /$, correlating with a feto-
Table I-Individual data points from 35 women for ductus venosus peak systolic velocity (PSV) and time-averaged velocity (TAV) before and after CVS

\begin{tabular}{|c|c|c|c|c|}
\hline \multirow[b]{2}{*}{ Case No. } & \multicolumn{2}{|c|}{$\operatorname{PSV}(\mathrm{cm} / \mathrm{s})$} & \multicolumn{2}{|c|}{$\mathrm{TAV}(\mathrm{cm} / \mathrm{s})$} \\
\hline & Pre-CVS & Post-CVS & Pre-CVS & Post-CVS \\
\hline 1 & $22 \cdot 3$ & $25 \cdot 3$ & $18 \cdot 3$ & $17 \cdot 5$ \\
\hline 2 & $23 \cdot 3$ & $28 \cdot 0$ & $16 \cdot 1$ & $20 \cdot 1$ \\
\hline 3 & $39 \cdot 7$ & 33.7 & $28 \cdot 8$ & $26 \cdot 9$ \\
\hline 4 & $40 \cdot 7$ & $41 \cdot 8$ & $27 \cdot 3$ & $28 \cdot 8$ \\
\hline 5 & $22 \cdot 6$ & $19 \cdot 9$ & $16 \cdot 0$ & 13.4 \\
\hline 6 & $35 \cdot 6$ & $23 \cdot 5$ & $27 \cdot 7$ & $15 \cdot 7$ \\
\hline 7 & $21 \cdot 8$ & $22 \cdot 6$ & 14.9 & 16.9 \\
\hline 8 & $18 \cdot 6$ & $23 \cdot 1$ & $10 \cdot 8$ & $17 \cdot 7$ \\
\hline 9 & $23 \cdot 2$ & $24 \cdot 2$ & 16.8 & $16 \cdot 6$ \\
\hline 10 & $25 \cdot 4$ & $21 \cdot 0$ & $18 \cdot 5$ & $15 \cdot 3$ \\
\hline 11 & $29 \cdot 3$ & $19 \cdot 5$ & $20 \cdot 4$ & $12 \cdot 8$ \\
\hline 12 & $33 \cdot 7$ & $20 \cdot 1$ & $23 \cdot 7$ & $14 \cdot 9$ \\
\hline 13 & $24 \cdot 9$ & $40 \cdot 2$ & $20 \cdot 6$ & $29 \cdot 5$ \\
\hline 14 & $40 \cdot 1$ & $25 \cdot 8$ & $27 \cdot 9$ & $20 \cdot 2$ \\
\hline 15 & $35 \cdot 6$ & $44 \cdot 1$ & 23.9 & $28 \cdot 9$ \\
\hline 16 & $35 \cdot 7$ & $29 \cdot 6$ & $25 \cdot 2$ & $22 \cdot 8$ \\
\hline 17 & $30 \cdot 5$ & $32 \cdot 2$ & $23 \cdot 7$ & $22 \cdot 3$ \\
\hline 18 & $29 \cdot 1$ & 39.9 & $22 \cdot 7$ & $28 \cdot 5$ \\
\hline 19 & $26 \cdot 4$ & $34 \cdot 7$ & $18 \cdot 5$ & $23 \cdot 9$ \\
\hline 20 & $44 \cdot 2$ & $46 \cdot 3$ & $31 \cdot 7$ & $31 \cdot 1$ \\
\hline 21 & $21 \cdot 1$ & $23 \cdot 0$ & $13 \cdot 9$ & $16 \cdot 3$ \\
\hline 22 & $24 \cdot 8$ & $34 \cdot 1$ & $16 \cdot 2$ & $24 \cdot 0$ \\
\hline 23 & $27 \cdot 1$ & $33 \cdot 6$ & $19 \cdot 0$ & $23 \cdot 9$ \\
\hline 24 & $48 \cdot 8$ & 35.8 & $34 \cdot 8$ & $24 \cdot 8$ \\
\hline 25 & $39 \cdot 3$ & $41 \cdot 7$ & $27 \cdot 9$ & $29 \cdot 6$ \\
\hline 26 & 23.9 & $30 \cdot 6$ & 18.0 & $21 \cdot 6$ \\
\hline 27 & $21 \cdot 4$ & $24 \cdot 9$ & 14.9 & 15.9 \\
\hline 28 & $31 \cdot 5$ & $31 \cdot 2$ & $24 \cdot 5$ & $22 \cdot 6$ \\
\hline 29 & $38 \cdot 1$ & $39 \cdot 2$ & $26 \cdot 6$ & $26 \cdot 6$ \\
\hline 30 & $22 \cdot 7$ & $24 \cdot 3$ & $15 \cdot 8$ & $18 \cdot 1$ \\
\hline 31 & $34 \cdot 2$ & $37 \cdot 1$ & $24 \cdot 1$ & $24 \cdot 9$ \\
\hline 32 & $42 \cdot 1$ & $28 \cdot 0$ & $30 \cdot 1$ & $22 \cdot 5$ \\
\hline 33 & $22 \cdot 1$ & $24 \cdot 9$ & $14 \cdot 9$ & $17 \cdot 2$ \\
\hline 34 & $71 \cdot 8$ & $26.1^{\circ}$ & 63.4 & 16.7 \\
\hline 35 & 33.0 & $20 \cdot 0$ & $23 \cdot 7$ & $15 \cdot 9$ \\
\hline 36 & $40 \cdot 3$ & 0.0 & $25 \cdot 2$ & 0.0 \\
\hline
\end{tabular}

maternal transfusion of $1.0 \mathrm{ml}$ or more; i.e., more than 21 per cent of feto-placental blood volume (Fig. 1). Two of these three pregnancies progressed uneventfully, resulting in the delivery of a healthy infant with a birth weight above the tenth centile. One of these cases (No. 34, Table I), presenting with an unusually high ductus venosus flow velocity prior to CVS, showed a marked reduction in ductus venosus flow velocity parameters after CVS: pre-CVS ductus venosus PSV: $71.8 \mathrm{~cm} / \mathrm{s}$, 
PDV: $58.9 \mathrm{~cm} / \mathrm{s}$, TAV: $63.4 \mathrm{~cm} / \mathrm{s}$, umbilical artery PI: $2 \cdot 3$; post-CVS ductus venosus PSV: $26 \cdot 1 \mathrm{~cm} / \mathrm{s}$, PDV: $20.1 \mathrm{~cm} / \mathrm{s}$, TAV: $16.7 \mathrm{~cm} / \mathrm{s}$, umbilical artery PI: $2 \cdot 4$. This was associated with a post-CVS MSAFP level of $667 \mathrm{kIU} / \mathrm{l}$, indicating a fetomaternal transfusion of approximately $1.0 \mathrm{ml}$. In the other surviving case (No. 35, Table I), postCVS flow velocities were slightly reduced with respect to those obtained prior to CVS: pre-CVS ductus venosus PSV: $33.0 \mathrm{~cm} / \mathrm{s}$, PDV: $29.9 \mathrm{~cm} / \mathrm{s}$, TAV: $23.7 \mathrm{~cm} / \mathrm{s}$, umbilical artery PI: 2.5 ; post-CVS ductus venosus PSV: $20.0 \mathrm{~cm} / \mathrm{s}$, PDV: $26.9 \mathrm{~cm} / \mathrm{s}$, TAV: $15.9 \mathrm{~cm} / \mathrm{s}$, umbilical artery PI: $2 \cdot 5$. In the third case (No. 36, Table I), fetal bradycardia $(60 \mathrm{bpm})$ was present and no peripheral flow velocities could be recorded $20 \mathrm{~min}$ following the CVS procedure. Fetal loss occurred 1 week later.

\section{DISCUSSION}

The potential risks associated with CVS have always been closely monitored. Recent reports of terminal transverse limb defects in newborns that had been subjected to CVS during pregnancy have led to a shift from CVS to amniocentesis (Saul, 1993).

Previous studies have demonstrated that the CVS procedure does not influence Doppler flow velocity patterns in the maternal uterine and umbilical artery (Zoppini et al., 1993).

The fetal venosus is instrumental in shunting well-oxygenated blood from the placenta to the left heart. The assumption was that if a feto-maternal transfusion were to occur, it would result in flow velocity changes in this vessel. The calculation of FMT volumes and expression in percentages of feto-placental blood volume represent only a rough estimate, since the rise in the MSAFP concentration is the single measured parameter: the other parameters (fetal haematocrit, fetal serum AFP concentration, feto-placental blood volume, and maternal blood volume) are derived from various studies (Los et al., 1989). A fetomaternal transfusion volume exceeding 10 per cent of feto-placental blood volume was established in six cases (16 per cent) and a feto-maternal transfusion volume exceeding 40 per cent of feto-placental blood volume was seen in three of these six cases. In animal experiments, a 70 per cent survival rate of fetuses after a feto-placental blood volume loss of 21 per cent has been established (Brace and Cheung, 1990). It has been speculated that in cases of a voluminous feto-maternal transfusion, at the same time a materno-fetal transfusion might compensate for the vascular volume loss (Los et al, 1993).

In the overall analysis, no significant change in ductus venosus flow velocities or umbilical artery PI could be established. When separating out the three cases with a marked feto-maternal transfusion, flow velocity changes in ductus venosus flow velocities were observed. In the two surviving cases, a feto-maternal transfusion of $1.0-1.4 \mathrm{ml}$ equalling approximately 40 per cent of fetalplacental volume was associated with a post-CVS reduction in the ductus venosus time-averaged velocity of more than 50 per cent. However, a comparable drop in the ductus venosus timeaveraged velocity occurred in cases 6,12 , and 24 (Table I) corresponding to an estimated fetomaternal transfusion volume of only $0.01-0.1 \mathrm{ml}$. In the third case with a feto-maternal transfusion of $1.1 \mathrm{ml}$, peripheral flow velocities were completely absent at the post-CVS Doppler examinations, whereas bradycardia was still discernible.

Most studies do not show significant differences in pre- and post-CVS Doppler flow velocity patterns of the fetal vessels under investigation. Our study suggests that voluminous feto-maternal transfusions may be associated with measurable differences between pre- and post-CVS Doppler flow velocities in the ductus venosus. However, similar velocity changes were associated with only small feto-maternal transfusions. Umbilical artery PI values remained unchanged.

\section{REFERENCES}

Brace, R.A., Cheung, C.Y. (1990). Fetal blood volume restoration following rapid fetal hemorrhage, $A m$. $J$. Physiol., 259-H, 567-573.

Brent, R.I. (1993). What is the relationship between birth defects and pregnancy bleeding? New perspectives provided by NICHD workshop dealing with the association of chorionic villus sampling and the occurrence of limb reduction defects, Teratology, 48, 93-95.

Burton, B.K., Schulz, C.J., Burd, L.I. (1992). Limb anomalies associated with chorionic villus sampling, Obstet. Gynecol., 79, 726-730.

Cohen-Overbeek, T.E., Jahoda, M.G.J., Wladimiroff, J.M. (1990). Uterine blood flow velocity waveforms before and after transcervical chorionic villus sampling, Ultrasound Med. Biol., 16, 129-132.

Firth, H.V., Boyd, P.A., Chamberlain, P., MacKenzie, I.Z., Lindenbaum, R.H., Huson, S.M. (1991). Limb 
abnormalities and chorion villus sampling, Lancet, 338, 51.

Firth, H.V., Boyd, P.A., Chamberlain, P.F., MacKenzie, I.Z., Morriss-Kay, G.M., Huson, S.M. (1994). Analysis of limb reduction defects in babies exposed to chorionic villus sampling, Lancet, 343, 1069-1071.

Gosling, R.G., King, D.H. (1975). Ultrasonic angiology. In: Marcus, A.W., Adamson, L (Eds). Arteries and Veins Edinburgh: Churchill Livingstone, 61-98.

Huisman, T.W.A., Stewart, P.A., Wladimiroff, J.W. (1992). Ductus venosus blood flow velocity waveforms in the human fetus-a Doppler study, Ultrasound Med. Biol, 18, 33-37.

Huisman, T.W.A., Stewart, P.A., Stijnen, T., Wladimiroff, J.W. (1993). Flow velocity waveforms in the ductus venosus, umbilical vein and inferior vena cava in normal fetuses at 12-15 weeks of gestation, Ultrasound Med. Biol., 19, 441-445.

Jahoda, M.G.J., Brandenburg, H., Cohen-Overbeek, T., Los, F.J., Sachs, E.S., Wladimiroff, J.W. (1993). Terminal transverse limb defects and early chorionic villus sampling: evaluation of 4300 cases with completed follow-up, Am. J. Med. Genet., 46, 483-485.

Kiserud, T., Eik-Nes, S.H., Blaas, H.G., Hellevik, L.R. (1991). Ultrasonographic velocimetry of the fetal ductus venosus, Lancet, 338, 1412-1414.

Kiserud, T., Eik-Nes, S.H., Blaas, H.G., Hellevik, L.R., Simensen, B. (1994). Ductus venosus blood velocity and the umbilical circulation in the seriously growthretarded fetus, Ultrasound Obstet. Gynecol, , 4, 109115.

Kloosterman, G. (1970). On intrauterine growth, Int. J. Gynaecol. Obstet., 8, 895-912.

Kofinas, A.D., McGuinness, T., Simon, N.V., King, K., Deardorff, J. (1992). Transabdominal chorionic villus sampling between 9.5 and 12 weeks of gestation has no effect on placental vascular resistance, J. Matern. Fetal Invest., 2, 131-78.

Los, F.J., Pijpers, L., Jahoda, M.G.J., Sachs, E.S., Reuss, A., Hagenaars, A.M., Wladimiroff, J.W. (1989). Transabdominal chorionic villus sampling in the second trimester of pregnancy: feto-maternal transfusions in relation to pregnancy outcome, Prenat. Diagn., 9, 521-526.

Los, F.J., Jahoda, M.G.J., Wladimiroff, J.W., Brezinka, C., Hagenaars, A.M. (1993). Fetal exsanguination by chorionic villus sampling, Lancet, 342, 1559.

Pijpers, L., Jahoda, M.G.J., Reuss, A., Wladimiroff, J.W., Sachs, E.S. (1988). Transabdominal chorionic villus biopsy in 2nd and 3rd trimester of pregnancy to determine fetal karyotype, $\mathrm{Br}$. Med. J., 297, 822-823.

Rodeck, C.H., Sheldrake, A., Beattie, B., Whittle, M.J. (1993). Maternal serum alphafetoprotein after placental damage in chorionic villus sampling, Lancet, 341, 500.

Saul, H. (1993). Bad timing puts babies at risk, New Sci, 138/1868, $12-13$.

Smidt-Jensen, S., Lundsteen, C., Lind, A.M., Dinesen, K., Philip, J. (1993). Transabdominal chorionic villus sampling in the second and third trimester of pregnancy: chromosome quality, reporting time and fetomaternal bleeding, Prenat. Diagn., 13, 957-969.

Stabile, I., Warren, R., Rodeck, C., Grudzinskas, J.G. (1988). Measurements of placental, decidual, and fetal proteins before and after chorionic villus sampling, Prenat. Diagn., 8, 387-391.

Zoppini, C., Ludominsky, A., Godmilow, L., Weiner, S., Maislin, G., Donnenfeld, A.D. (1993). Acute hemodynamic effects induced by chorionic villus sampling: a preliminary investigation, Am. J. Obstet. Gynecol, 169, 902-907. 